\title{
Discussion on the Application of Bamboo in Architectural Design
}

\author{
Mengtian Zhang \\ University of Science and Technology LiaoNing \\ Anshan, China
}

\author{
Hao Ying* \\ University of Science and Technology LiaoNing \\ Anshan, China \\ *Corresponding Author
}

\begin{abstract}
Since the 20th century, forest resources have been cut down endlessly while the world's economy is developing rapidly. The earth is becoming warmer and the haze is serious. In the 21st century, we must rationally coordinate the relationship between human, natural environment and development. Now most designers design from the perspectives of energy, ecology, materials, and environmental protection, and consider the relationship between materials, space and psychophysiology of human. China has rich bamboo resources and its production ranks first in the world. Therefore, the use of bamboo resources has its own characteristics, which can not only maintain the ecological balance but also save the economic expenditure. Bamboo is ideal material for architectural design. In this paper, the application of bamboo materials in architectural design, various characteristics of bamboo materials, as well as practical cases and design innovations in traditional and modern architecture are analyzed. And this paper tries to find the value of bamboo in architectural design from the macro point of view. This paper also has confirmed the results of the study through multiple practical cases. In the near future, bamboo will certainly become one of the major materials in contemporary architectural design, and it will be uniquely innovative in design performance, which will make the entire construction sector alive and vital.
\end{abstract}

Keywords-ecology; materia; value; innovation

\section{INTRODUCTION}

\section{A. Global Environment Deterioration and Resource Depletion}

As global temperatures continue to rise, the amount of carbon dioxide in the air continues to double, the haze situation becomes more and more serious, and the global environment is deteriorating. A large number of earth resources are endlessly mined and destroyed, which makes the earth's resources gradually depleted. The energy consumption and environmental pollution brought about by the processing, construction, and abandonment of these resources in the later period pose a threat to the global environment. Bamboo is taken from nature. Most importantly, it is renewable, and its waste could be attributed to nature once again, forming a perfect cycle. Compared with other new materials, it is a typical renewable, and environmentally friendly material. China's exploitation and utilization of bamboo materials was the earliest, and China has always been known as the "Bamboo
Kingdom." Therefore, we are easily sourced and resource-rich. Bamboo has a low price, high flexibility, and strong resistance to bending, which are well reflected in architectural design.

\section{B. The Status of Bamboo Development}

Bamboo is a green material. It has a fresh color and natural texture, giving people a sense of natural simplicity and calm, and brings relaxation and relief to busy people. In addition, bamboo represents a gentlemanly character in our longstanding culture. In recent years, bamboo has begun to emerge in architectural, landscape, interior and other areas. China has also made great achievements in the application of bamboo in architectural design. Many domestic and foreign architects designed and completed a number of famous bamboo buildings by using bamboo materials. So far, there are a number of bamboo building projects under development and implementation.

\section{Research Status of Bamboo at Home and Abroad}

1) Domestic research status: Since the beginning of the new century, all countries in the world have begun to study green building materials. As an outstanding eco-friendly material, bamboo has been used by more designers for innovative research. In some areas of southern China, bamboo has become an important foundation for local economic and social development. Our country has also been paid more attention to the application of bamboo materials in design. Because China has made outstanding achievements in the application of bamboo for a long time, the International Bamboo and Vine Organization has set up its headquarter in China.

2) Research status in foreign countries: The Asia-Pacific Bamboo District is the largest bamboo area in the world, and $64 \%$ of the bamboo species are native to Southeast Asia. The Americas and Africa also have their own bamboo areas, so various types of bamboo research institutions have been established in these areas. India is the country with the most abundant bamboo resources except China and has established the National Bamboo Development Committee. In the past 10 years, the bamboo industry in the United States has developed rapidly. The "Bamboo Association" has been established and an action called "American Bamboo" has been implemented. 
Among them, the research on bamboo construction is more prominent in foreign countries.

\section{Characteristics Analysis of Bamboo}

1) Ecological characteristics of bamboo: Bamboo has a strong ability to reproduce. It has strong regeneration, and soon will become a bamboo forest. The research data shows that the energy consumption of bamboo in the construction of two buildings of the same area is one-fifth of the energy consumption of steel, one-eighth of the energy consumption of concrete, and one-third of the energy consumption of wood. Different from the serious pollution caused by the traditional production process of building materials, the early collection and processing of the bamboo materials, the construction of the buildings in the later period, and the waste disposal process will cause very little pollution to the environment. Secondly, bamboo can effectively regulate the temperature and humidity of the air, and it has a good absorption and decomposition of harmful gases in the air. Bamboo is a product of nature. It is an ecological cycle from its growth to wither. Bamboo is environmentally friendly and cheap, so it is often used in architectural design.

2) Cultural Characteristics of Bamboo: Chinese bamboo culture is deeply ingrained, and bamboo culture can also reflect the traditional Chinese cultural characteristics. The shape of bamboo is high and straightforward. Moreover, "Joints" is a unique characteristic of bamboo. The hollow bamboo joints are often compared to gentlemen who do not fear power. The bamboo joints continue to grow and grow, which represents increasing and successful career. Bamboo is hollow, which represents modesty in our traditional culture. There is nothing in the abdomen of bamboo, so it needs to continuously absorb nutrition and energy from the outside world and constantly enrich itself. This is the most remarkable feature of bamboo and is also the traditional virtue of our Chinese nation.

3) Structural characteristics of bamboo: Bamboo is very flexible and strong. Among the materials with this strength, bamboo is one of the most cost-effective materials. Bamboo has high tensile strength. It bends with the wind, but it will not break. Bamboo has higher tensile strength and compressive strength than wood. Therefore, bamboo has excellent conditions for use in building materials. The flexibility and strength of bamboo itself is very suitable for the development of structural members such as beams, plates, columns, and walls in building structures. Because of its excellent flexibility, bamboo is a preferred building material in earthquake-prone areas. Bamboo is a masterpiece of nature. Suitable for a variety of production and processing, if bamboo is reasonably applied, it will become the best construction materials in the construction industry.

\section{APPLICATION OF BAMBoo IN ARCHITECTURAL DESIGN}

\section{A. Application of Bamboo in Traditional Buildings}

Bamboo has been used as a building material for thousands of years. As early as the Neolithic Age, bamboo has been used for construction. Bamboo itself has good flexibility and high hardness, and it is widely used in buildings. In the traditional bamboo construction, bamboo is usually the most basic building material and building components. It is mainly used for load-bearing materials such as walls and floors [2].

The traditional representative bamboo construction in our country should be bamboo bars. Due to the high temperature and dampness in southern China, bamboo materials are widely used in southern China. Because bamboo can regulate indoor air, purify the air and make the indoor cool in winter and cool in summer, which is suitable for the southern climate, there are many traditional bamboo buildings in southern China [3].

\section{B. Application of Bamboo in Modern Buildings}

In recent years, people have paid more and more attention to the value of bamboo in architecture and widely used it in architecture. For example, in the shortlist for the 2017 Taipei Design Awards, a fully constructed bamboo woven architectural landscape, "The Knitted Pier". The idea of the program stems from the changes in bamboo weaving. The beads and bamboo pieces mutually restrict and support each other, and the stress is transmitted. The simplified structures in the air have the strength and stability. It has designed a new way of construction from the traditional skills and traditional life.

As the figures show: "Fig.1", "Fig. 2"

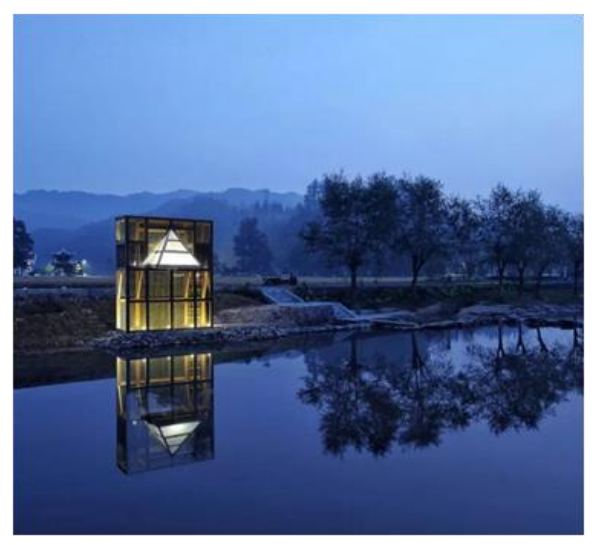

Fig. 1. Night view of the woven wharf. 


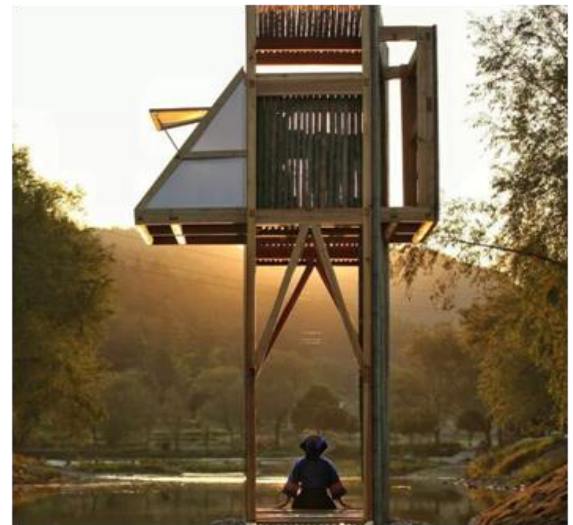

Fig. 2. Weaving wharf.

As technology continually develops, architects try to apply new technologies to architectural design and construction. They combine different materials with bamboo, and treat the bamboo in various ways to make it more durable and waterproof, making the most of bamboo's characteristics. For example, in Vietnam Hay Hay restaurant and bar, the restaurant's main structure is designed by bamboo. The rectangular design of the restaurant consists of 29 conical pillars and 2 bamboo domes. All columns are connected by a sloping roof composed of straight bamboo in the grid system. A glass facade supported by concrete columns is designed to obtain a space that could completely close the space, but still connected to the surrounding external landscape. The bamboo used in this resort is naturally treated in situ. The process of treating bamboo includes fire bending, soaking in water and fumigation. This program took 4 months to achieve better bamboo quality.

\section{As figures show: "Fig. 3", "Fig.4"}

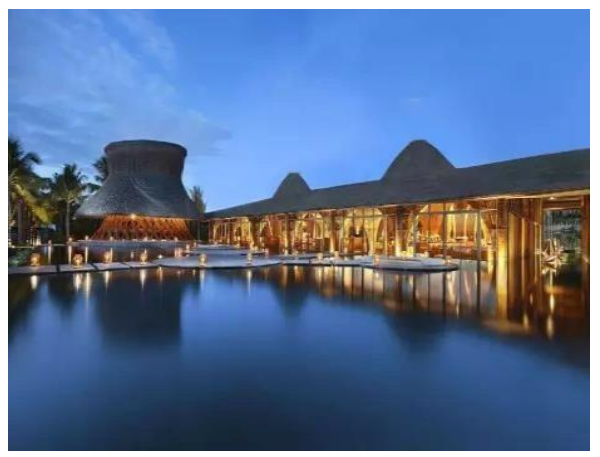

Fig. 3. Vietnam HayHay Restaurant.

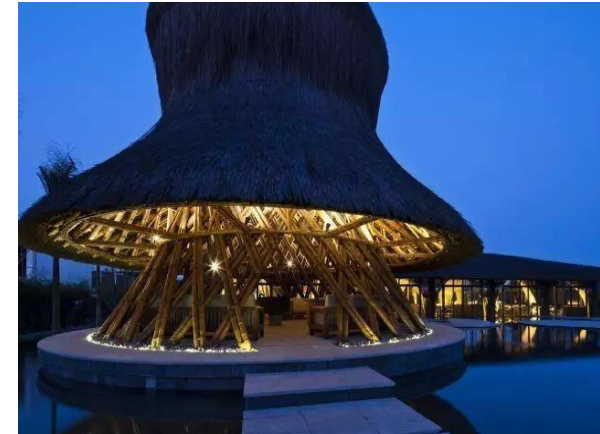

Fig. 4. Vietnam HayHay Bar.

\section{The VAlue OF BAMBOO APPLIED IN ARChITECTURAL DESIGN}

\section{A. Aesthetic Value}

Bamboo, whether as a building's overall form or as a building structure's material, has its own unique beauty. The natural growth state of bamboo is very beautiful. Among them, the bamboo shoots grow upright, the bamboo poles are straight, and the bamboo leaves are so graceful and graceful, like slender beauty. According to the changes of season and time, the color of bamboo is also different. The bamboo that has just been cut shows fresh green, and if it is left for a period of time after cutting, it will gradually turn yellow from green. The longer it has been left, the darker the color. At first green brings fresh, natural, and calm. People feel close to nature. The yellow color in the later period gives people a feeling of warmth, comfort and closeness. In addition, the texture of bamboo is natural and beautiful. No matter how you cut it, the cross section is natural. These are the reasons why bamboo is loved by designers.

\section{B. Regional Cultural Value}

Because of its growing environment, bamboo is a building material with typical geographical features. The famous bamboo buildings in each area are affected by the regional culture and have distinctive regional cultural values. Just like the Roc Von bamboo restaurant in Hanoi, Vietnam, the building is 30 kilometers away from Hanoi, connecting Hanoi and the main road of peace. To enjoy and rest a long journey, the area is popular with buses and cars to stop. It is also a destination for Greeks to enjoy day trips. The restaurant is located beside the road. In order to create an intimate space that protects guests from the busy road, the restaurant is designed below the road. After descending from the busy road to the dining space, guests are facing a natural lake, above which is a bamboo vault. 12 bamboo columns extend upwards to support the semi-outdoor dining area roof structure. The arcshaped design with a center stage is prepared for the use of events and has an intimate atmosphere. This building provides guests with space to feel close to the local culture of North Vietnam. Open space applications and the use of natural materials meet the required connections.

As figures show: "Fig. 5", "Fig. 6", "Fig. 7" 


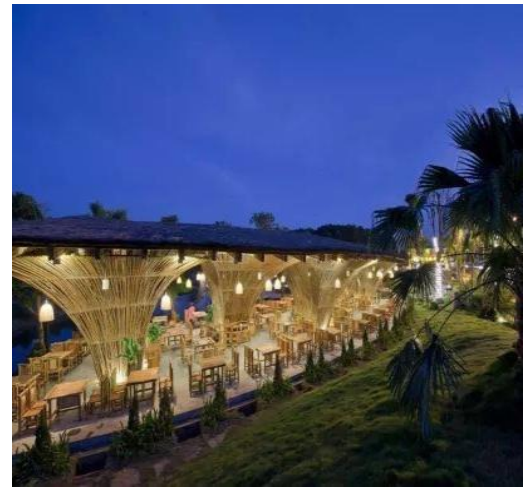

Fig. 5. Night view of RocVon Bamboo Restaurant in Hanoi, Vietnam.

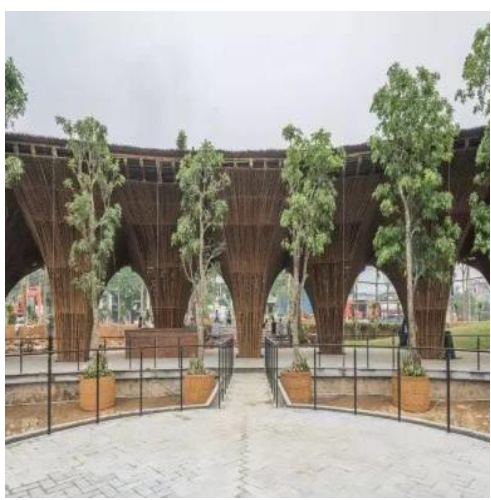

Fig. 6. The frontage of RocVon Bamboo Restaurant.

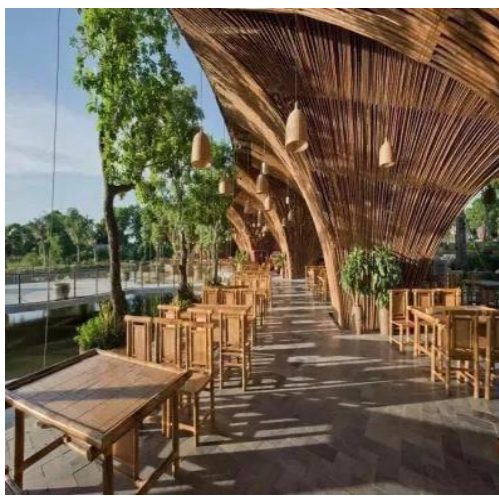

Fig. 7. The side of RocVon Bamboo Restaurant.

\section{Ecological Value}

The warming of the earth and the deterioration of the environment have led people to pay attention to a low-carbon and environmentally friendly lifestyle. In the construction industry, designers have also paid more attention to the green performance of materials. According to the characteristics of the material itself, bamboo has a great advantage in performance. It has a reproducible characteristic and will soon be able to present a vibrant scene. Compared with building materials, bamboo materials have low energy consumption, no pollution, and no waste during processing. Bamboo can also adjust the temperature and humidity in the temperature and absorb ultraviolet light and air pollutants. And bamboo waste after application, can also be environmentally degraded to the earth as a fertilizer. It is the most environmental cycle. Therefore, bamboo is the material that has the most ecological value and is most environmentally friendly [4]. For example, the "green campus" design in Bali, Indonesia, has attracted widespread attention and praise throughout the world. It is one of the most beautiful campuses imaginable. All are bamboo buildings, surrounded by lush organic gardens, and the Love River crosses the campus. The design of the campus minimizes the damage to the environment. A small number of trees are cut down. Most of them are made of bamboo as the main building material. The local renewable natural resources such as thatched grass, volcanic rocks, and rammed earth are also used. Campus open-air buildings can absorb enough natural light to keep the air flowing. Due to the large amount of bamboo used in the campus, the ceiling fans and innovative enclosed air-conditioning hood systems, even in the hottest season in the region the campus is kept cool.

As figures show: "Fig. 8", "Fig. 9", "Fig. 10"

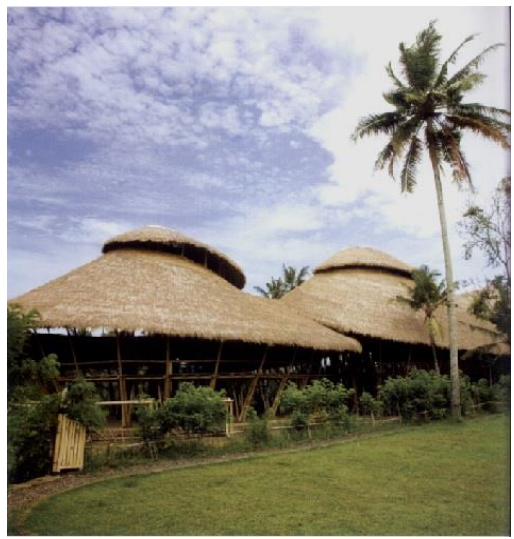

Fig. 8. Green campus in Indonesia.

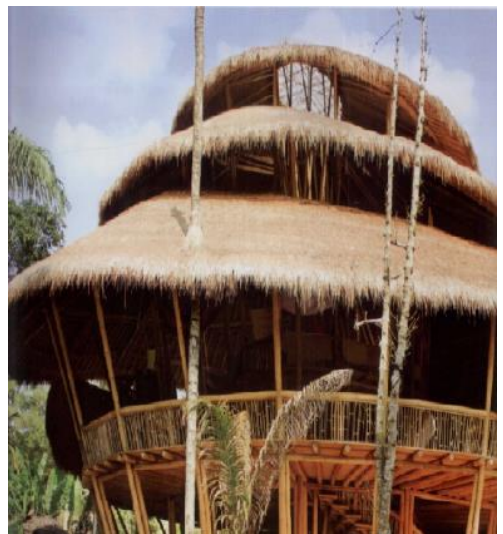

Fig. 9. Open-air buildings on green campus. 


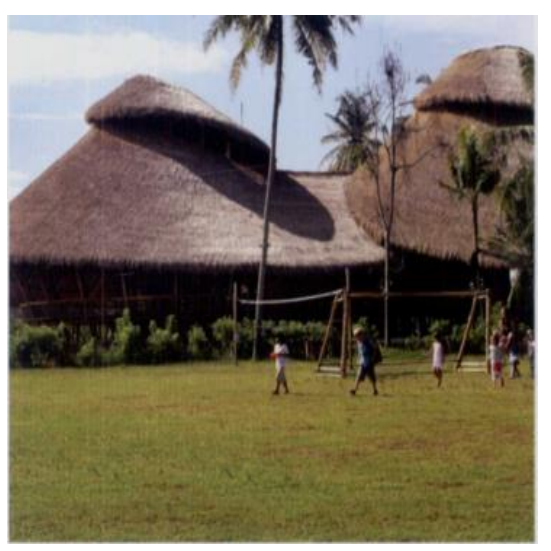

Fig. 10. The playground of green campus.

\section{CONCLUSION}

Nowadays, the global environmental pollution is serious and earth is getting warmer. People have gradually attached significance to the ecological environment. Therefore, the choice of building materials is a basic issue. As an environmentally friendly and renewable material, bamboo is one of the most frequently selected materials in today's architectural design. Architecture is the container of the soul and the solidified music. The artistic temperament contained in the bamboo material itself makes the architecture elegant and indifferent. The focus of this article is on the research of bamboo in architectural design. The development status of bamboo materials and the characteristics analysis of bamboo materials are studied. Bamboo's ecological, cultural, and structural characteristics are fully reflected in specific cases. Finally, this article summarizes the characteristics of bamboo and further studies the value of bamboo in architectural design.

\section{REFERENCES}

[1] Zheng Beiying. The "Bamboo Kingdom" in the World Expo Site Feelings of a promising bamboo industry[J]. Graden, 2011(1):37-40.

[2] Sheng Nan. Application of Bamboo Materials in Construction[D]. Donghua University, 2012

[3] Liu Su. 'Civilization of Construction: Chinese Traditional Culture and Traditional Architecture', Tsinghua University Press,2014.4.1

[4] Jiang Zehui, Fei Benhua, Wang Zheng, Sun Zhengjun, Guo Wenjing. 'A Preliminary Report on the Study of New Bamboo Structures: Research and Application of Structural Composite Bamboo materials'2003 